\title{
World's academies seek a sustainable future
}

\section{Robert Triendl, Tokyo}

Governments were urged last week to increase their investment in areas of basic science and technology related to sustainable development. This was the message to emerge from a four-year study of sustainability by the world's scientific academies, whose results were presented at a meeting in Tokyo.

It was also agreed that the secretariat for the InterAcademy Panel on International Issues (IAP), which set up the study and has up to now been run from the Royal Society in London, will move to the Third World Academy of Sciences (TWAS) in Trieste, Italy. A spokesman for TWAS said the academy was "delighted".

The Italian government, which already provides backing for both TWAS and the International Centre for Theoretical Physics, is expected to support the housing of the IAP secretariat in a villa being made available by regional authorities.

A statement at the end of the meeting on the need for more research into sustainable development has been criticized by some for being too vague, but others say the wording was deliberately kept open. "The details will have to be filled out over the next year," says

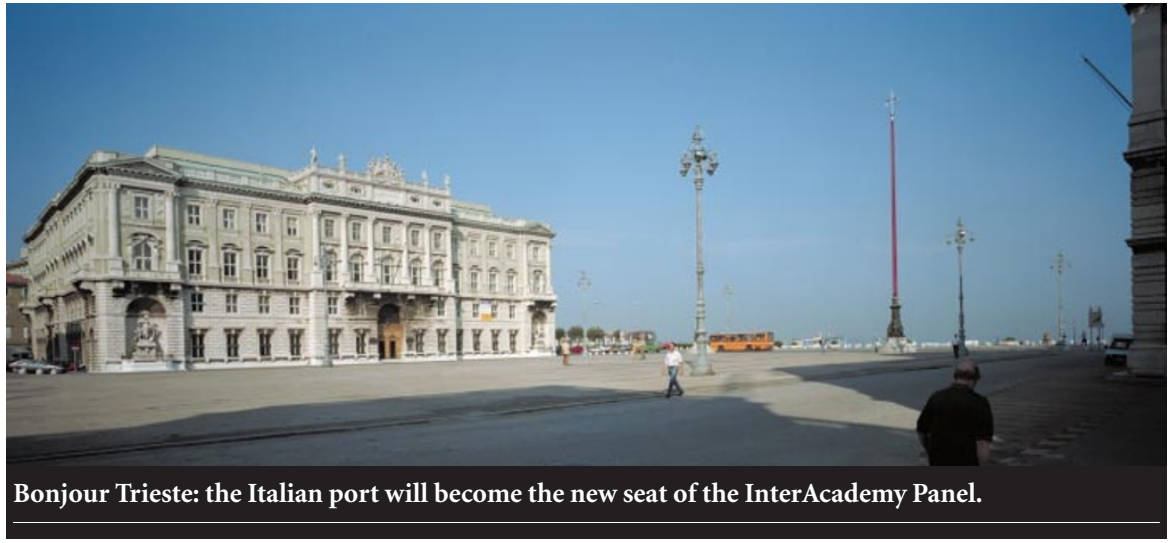

Sherwood Rowland, foreign secretary of the US National Academy of Sciences and outgoing co-chairman of the IAP.

According to Yves Quéré, foreign secretary of the French Academy of Sciences and one of the two new co-chairmen (the other is Eduardo Krieger, president of the Brazilian Academy of Sciences), one goal of the IAP will be to organize projects around 'clusters' of academies sharing common interests. He cites an existing collaboration between French and Swedish scientists on mother/infant health. Other topics could include school science education and the biodiversity of tropical rainforests.

The IAP will work closely with the new InterAcademy Council, set up in Tokyo. Based at the Royal Netherlands Academy of Arts and Sciences in Amsterdam, the council will provide scientific expertise to international organizations such as the United Nations and the World Bank (see Nature 405, 268; 2000).

In contrast, the IAP will continue primarily to help its members to fulfil their consultative and administrative functions within their home countries.

http://www.nationalacademies.org/iap 